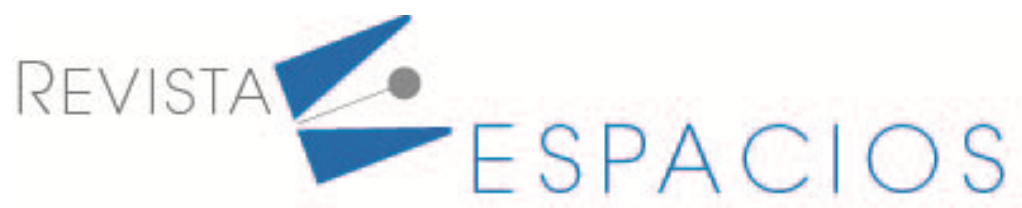

Vol. 42 (10) $2021 \cdot$ Art. 9

Recibido/Received: 24/02/2021 • Aprobado/Approved: 18/05/2021 • Publicado/Published: 30/05/2021

\title{
Las microfinanzas y las mujeres afro de la ciudad de Guayaquil - Ecuador
}

\section{The microfinances and afro women of the city of Guayaquil}

\begin{abstract}
SÁNCHEZ, Olinda C. ${ }^{1}$
Resumen

El estudio analiza la importancia de las microfinanzas y su contribución al desarrollo de las mujeres afro de la ciudad de Guayaquil cuyo problema principal radica en la falta de acceso al financiamiento por considerarlas excluidas del sistema económico al no contar con las garantías que las respalden, asociado a tensiones de género, formación, etnia, sin tomar en cuenta sus capacidades y habilidades productivas. Palabras clave: discriminación, microcrédito, pobreza
\end{abstract}

\begin{abstract}
The study discusses the importance of microfinance and its contribution to the development of Afro women of the city of Guayaquil whose main problem lies in the lack of access to finance because they are excluded from the economic system by not counting with the guarantees that support them, associated with gender tensions, ethnic training, without taking into account their productive capacities and habilities.
\end{abstract}

Key words: discrimination, microcredit, poverty

\section{Introducción}

Según los datos del último Censo de Población y Vivienda del año 2010, en el país hay 1.041.559 afroecuatorianos, que representan el 7,2\% del total de la población (Instituto Nacional de Estadísticas y Censos, 2010), siendo Guayas la segunda provincia con mayor presencia afroecuatoriana y Guayaquil la ciudad que concentra el mayor número de afros.

El flujo de afrodescendientes a Guayaquil comienza en el siglo XX, cuando el presidente Eloy Alfaro trajo un grupo de jamaiquinos como mano de obra especializada para la construcción del ferrocarril trasandino.

A partir de los años cincuenta, se acrecentó el número de esmeraldeños migrantes que llegaron a Guayaquil, esperanzados en mejorar su calidad de vida. La formación de asentamientos humanos con fuerte presencia negra, en los suburbios del puerto, aumentó en las décadas siguientes y los afrodescendientes empezaron a reivindicar su identidad.

En los años sesenta, ya se conocen los "barrios negros" organizados en precooperativas nacidas al fragor del clientelismo político, como resultado de "invasiones" en zonas de manglares y sabanas anegadas. Así se inicia el

\footnotetext{
${ }^{1}$ Docente Investigadora. Facultad de Ciencias Económicas. Universidad de Guayaquil, Ecuador. olinda.sanchezg@ug.edu.ec https://orcid.org/0000-00025045-089X
} 
poblamiento de lo que actualmente se conoce como el barrio del Cristo del Consuelo, al sur de la ciudad, habitado mayoritariamente por familias afroecuatorianas.

En la década petrolera, los años setenta, el proceso de concentración urbana de los negros en los sectores periféricos se acentuó, lo que incidió en la reconstitución del mapa topográfico y sociourbano de Guayaquil.

En los años ochenta, cuando madura la organización comunitaria, se multiplican las cooperativas y germinan nuevos barrios, cuyos nombres aluden a la herencia ancestral: La Marimba, Nigeria, Esmeraldas Chiquito, África Mía. Otros sectores de importante presencia afro son: Pablo Neruda y Cristal, en el Guasmo; y Cenepa, en la Isla Trinitaria.

En estos barrios, la riqueza de la cultura afroecuatoriana exteriorizada en la tradición oral, gastronomía, música y religiosidad, se muestra en todo su esplendor. Cuando la ocasión hace posible el encuentro de familiares, amigos y vecinos, florecen las décimas, resuenan los tambores, se ensancha el ambiente de jolgorio, y un Guayaquil profundo manifiesta, en el roce gozoso de los cuerpos, la huella de su profunda africanía.

Los registros de la Dirección de Terrenos del Municipio de Guayaquil al 2020 destacan que la población afrodescendiente de la ciudad se concentra al sur en Cristo del Consuelo, Esmeraldas Chiquita, Nigeria y Eloy Alfaro, al noroeste en Cooperativas Mélida y Sergio Toral y al oeste de la ciudad en la parroquia urbana Febres Cordero.

Yunus M. (2006) plantea que si alguien de la familia tiene que pasar hambre, existe una ley no escrita que estipula que esa persona ha de ser la madre. También es ella la que padece la experiencia traumática de no poder amamantar a su pequeño o a su pequeña durante las épocas de hambruna y escasez. A pesar de estas adversidades, resulta evidente que las mujeres más desposeídas se adaptan más rápidamente y mejor al proceso de autoayuda que los hombres en su misma situación. Aunque no sepan leer ni escribir y rara vez hayan tenido permiso para salir solas de sus casas, las mujeres pobres saben ver más lejos y están dispuestas a trabajar más para sacarse a ellas mismas y a sus familias de la pobreza. Prestan más atención, preparan a sus hijos para que tengan una vida mejor y evidencian un rendimiento más constante que los hombres.

También sostiene Yunus que cuando una mujer indigente empieza a ganar unos ingresos, sus sueños de éxito giran invariablemente en torno a los hijos. Su segunda prioridad es el hogar familiar. Quiere comprar utensilios diversos, reforzar la techumbre o buscar un lecho para ella y su familia. Un hombre, sin embargo, tiene una lista de prioridades completamente distinta. Cuando un padre indigente gana unos ingresos adicionales, se centra más en sí mismo. Así pues, el dinero que entra en un hogar a través de una mujer reporta más beneficios para la familia en su conjunto. Si las metas del desarrollo económico son mejorar el nivel de vida general, reducir la pobreza, crear oportunidades de empleo digno y reducir la desigualdad, entonces lo natural es trabajar a partir de las mujeres. Ellas no sólo constituyen la mayoría de las personas pobres, de las subempleadas y de las económica y socialmente desfavorecidas, sino que mejoran con mayor facilidad la situación tanto de los hijos como de los hombres.

La presente investigación nace como una necesidad personal por conocer el entorno en el cual desenvuelven su vida y sus actividades las mujeres afro de Guayaquil, ciudad pujante cuyos ciudadanos se enfrentan cotidianamente a las tendencias negativas del sistema económico vigente y donde las mujeres en general, y en especial las de esta etnia, han sido generacionalmente violentadas de forma física, social y económica.

El limitante principal para las mujeres afroecuatorianas es la falta de acceso al financiamiento, al no ser consideradas sujeto de crédito por no contar con las garantías y avales que las respalden. Pero el problema es aún más grave que la exclusión puramente económica y viene generalmente asociado a problemas de segregación e individualismo en términos posesivos. 
En este contexto, este artículo tiene como objetivo difundir los obstáculos que tienen las mujeres afro en su proceso de desarrollo personal y familiar, además de sugerir que desde la academia se analice la forma en que se desarrolla la lucha de estas mujeres por desarraigar su dependencia económica y lograr su empoderamiento a través de la organización colectiva de economía popular y solidaria, utilizando como instrumento de democratización del dinero: las microfinanzas.

\subsection{Las mujeres y las microfinanzas}

Las microfinanzas constituyen una forma de democratización del dinero hacia los sectores normalmente excluidos del sistema financiero convencional. Dentro de este grupo, las mujeres pobres son consideradas la parte más vulnerable de la cadena.

Se toma como punto de partida de las microfinanzas, la creación del Banco Grameen en 1983 en la ciudad de Bangladesh en India, donde el profesor Muhammad Yunus, Premio Nobel de la Paz 2006, fue su fundador. Un banco dedicado a suministrar prestamos minúsculos a las personas más pobres. Su objetivo no era simplemente ayudar a que los pobres sobrevivieran, sino generar un mecanismo de ignición de la iniciativa y el espíritu emprendedor que les ayudara a salir por sí mismos de la pobreza. Aquella idea nació un día de 1976 cuando, de su propio bolsillo, Yunus prestó una cantidad equivalente a 27 dólares a cuarenta y dos habitantes de una aldea de la localidad. Eran fabricantes de taburetes que no necesitaban más que el crédito suficiente para adquirir la materia prima para su oficio. El préstamo de Yunus les ayudó a romper el devastador circulo de la pobreza y a cambiar sus vidas. El Banco Grameen parte de la firme creencia de que el crédito debería estar aceptado como un derecho humano más y, sobre ella, erige un sistema en el que quien no posee nada recibe la máxima prioridad a la hora de obtener un préstamo. Esta metodología no se fundamenta sobre el estudio o la valoración de las posesiones materiales de una persona, sino sobre el potencial de ésta. Grameen cree que todos los seres humanos, incluidos los más pobres, están dotados de un potencial infinito: presten dinero a las personas pobres, fomenten una serie de principios financieros sensatos que regulen sus vidas y ellas se ayudarán a sí mismas. Y es así como llevadas a la práctica, las teorías de Yunus funcionan. El Banco Grameen ha proporcionado más de 2.500 millones de dólares en microprestamos a más de dos millones de familias de Bangladesh rural, donde casi el 96\% de sus clientes son mujeres y el índice de reembolso de los préstamos es prácticamente del 100\%. (Yunus M. , 2006)

La Secretaria de Economía del Gobierno Mexicano define a las microfinanzas como "otorgar a las familias más pobres, pequeños créditos (microcréditos) para apoyarlos económicamente en actividades productivas (negocios-autoempleo)". Mientras que el Asian Development Bank lo define como: la oferta de servicios financieros tales como: depósitos, préstamos, servicios de pagos, transferencias de dinero, seguros para las casas y microempresas de los pobres o personas de bajos ingresos (Araque \& Vaca, 2011).

En América Latina sólo el $49 \%$ de las mujeres tienen una cuenta bancaria, el 11\% ahorra y el 10\% dispone de crédito, valores que para los hombres representan el $54 \%, 16 \%$ y el $13 \%$ respectivamente, señala un informe de la CAF, en base a datos del Banco Mundial. Sólo el 30,7\% de las mujeres adultas de la región dijo haber recibido algún crédito en el último año: lo anterior incluye instituciones financieras, prestamistas informales, familiares y amigos. Y los negocios son el último propósito para las solicitudes por parte de mujeres. Las prioridades son salud y educación (Corporación Andina de Fomento, 2018).

En Ecuador, el gobierno se ha focalizado en el segmento denominado "Economía Popular y Solidaria" -que fue definido por la Constitución en 2008- y que busca ampliar la inclusión financiera mediante servicios financieros ofrecidos por cooperativas de ahorro, asociaciones crediticias, bancos comunales y organizaciones sin fines de lucro (ONGs) (Portal FINDEV, 2020). 
Las mujeres, cuando se financian, lo hacen a través de instituciones de "microfinanzas" en un 61,9\%. El crowdfunding y los créditos solidarios son una de las principales fuentes de financiamiento, con una participación del $80 \%$ y montos de 300 dólares. El monto promedio en las instituciones de microfinanzas es de 1.178 dólares y la tasa media regional de interés es del $28,6 \%$ (BID, 2010).

El artículo titulado "Una red de chulqueros es capaz de manejar más de \$1,5 millones" refiere a Roberto Villacreses, analista del Instituto Ecuatoriano de Economía Política, quién manifiesta que la acogida que tienen los "prestadiario" se da porque muchas de las tasas de interés están reguladas, lo que motiva que sea muy difícil acceder a un crédito normal o legal. (Diario EL TELÉGRAFO, 2012) Siendo esta la forma que ellas encuentran para poder financiar sus gastos de forma inmediata.

\section{Metodología}

El enfoque de investigación es cualitativo, con un diseño etnográfico que según (Hernández-Sampieri \& Mendoza Torres, 2018) se refiere aquel que estudia grupos, organizaciones, comunidades y otras colectividades, analizando elementos simbólicos y produciendo categorías y temas culturales, que son vinculados. Para el efecto se hará uso de los datos proporcionados en la página web del Banco Central del Ecuador sobre la experiencia de desarrollo de base de las mujeres organizadas de la Isla Trinitaria, de la ciudad de Guayaquil, durante el periodo 2003 - 2017. Caso: Agrupación Afroecuatoriana "Mujeres Progresistas".

\section{Resultados y discusión}

\subsection{Las mujeres afro frente al crédito}

Las mujeres afroecuatorianas que habitan en la ciudad de Guayaquil son en su mayoría madres solteras, mujeres desempleadas o que han sido víctimas de violencia intrafamiliar. Sus condiciones frente al acceso a los microcréditos para emprender productivamente no se diferencian mucho de las que viven las mujeres de la región latinoamericana que principalmente se enfrentan a barreras de tipo social, requerimientos de garantías, montos de préstamo y escasez de productos crediticios compatibles con su condición económica.

Su acceso al financiamiento ha sido bastante difícil, teniendo muchas veces que recurrir a préstamos de familiares, amigos, pero principalmente a los ofrecidos por los llamados "chulqueros", quienes cobran tasas del $20 \%$ de interés mensual pero les aseguran un crédito fácil y sin trámites engorrosos.

Muchas mujeres además son beneficiarias del Bono de Desarrollo Humano a través del cual pueden aplicar al Crédito de Desarrollo Humano bajo dos modalidades: un crédito Individual por un monto de 600 dólares y un crédito asociativo por un valor de 1200 dólares, dinero que deberá ser invertido exclusivamente en mejorar las condiciones de vida familiares por medio de la puesta en marcha de un emprendimiento. Junto con el crédito, se brinda además capacitaciones, acceso a ferias para promocionar sus productos, seguimiento y control de las actividades por parte de los técnicos del Ministerio de Inclusión Económica y Social.

Además, se encuentran las ONG que dadas sus condiciones de cercanía a los territorios, pueden trabajar de forma más específica con las mujeres, conociendo de primera mano sus necesidades y brindando alternativas puntuales y eficaces. Además de cumplir con una de las características fundamentales de las microfinanzas .como es la de acercar los servicios financieros a las personas, siendo las instituciones quienes van hacia las beneficiarias y no viceversa, teniendo como objetivo primordial proporcionarles las herramientas que les permitan generar una fuente de ingreso para ellas y sus familias, pero que sobretodo propicien su empoderamiento y se conviertan en un incentivo para su crecimiento personal. 
En el artículo "Mujeres afro piden mayor reconocimiento" se hace referencia a Ayda Quintero, Presidenta de la Cámara de Afrodescendientes, quién reconoce que antes las mujeres se dedicaban a ser lavanderas pero ahora muchas se encuentran en cargos altos en la Asamblea y ministerios. "Antes teníamos miedo a emprender, pero ahora nos damos cuenta que es la única forma de superarnos" (Diario EL TELÉGRAFO, 2020).

Es relevante asegurar la permanencia y continuidad de los estudiantes, garantizando herramientas de desarrollo individual, aprendizaje social y motor de cambio en situaciones de pobreza. (Hogar de Cristo Ecuador, 2012), como método para separar a los niños, niñas y adolescentes de los vicios, pandillas, delincuencia, embarazos no deseados y asegurarles un mejor porvenir, para ellos y sus familias.

\subsection{Impacto de las microfinanzas en las mujeres organizadas de la Isla Trinitaria. Caso: Agrupación Afroecuatoriana "Mujeres Progresistas"}

Las microfinanzas han generado un impacto social muy fuerte en las mujeres afro de la zona a través de mejoras en varios aspectos de su vida a nivel económico, empresarial, tecnológico, formativo y de empoderamiento.

Figura 1

La Isla Trinitaria. Guayaquil, Ecuador

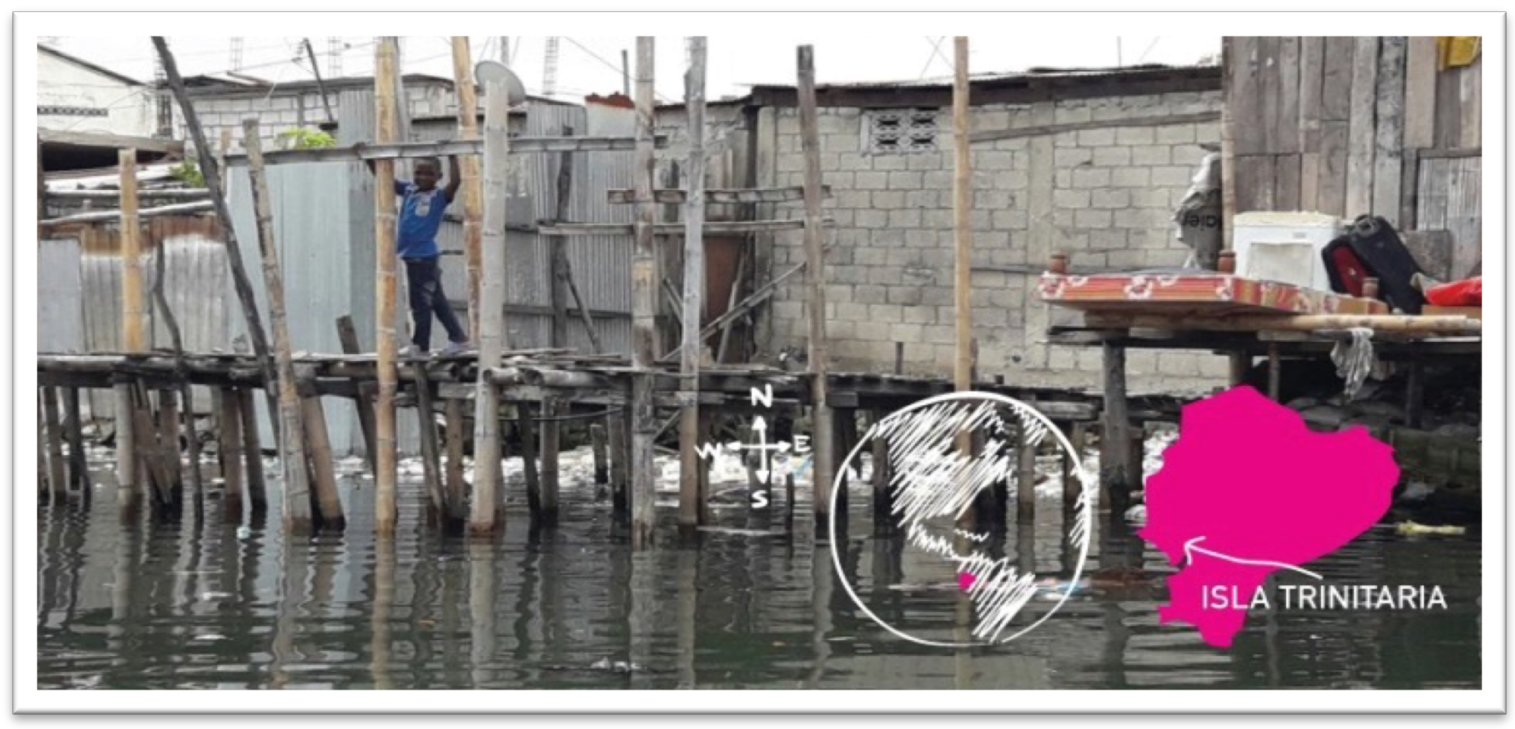

Fuente: https://www.bce.fin.ec (2017) 
Figura 2

Lideresas de la agrupación

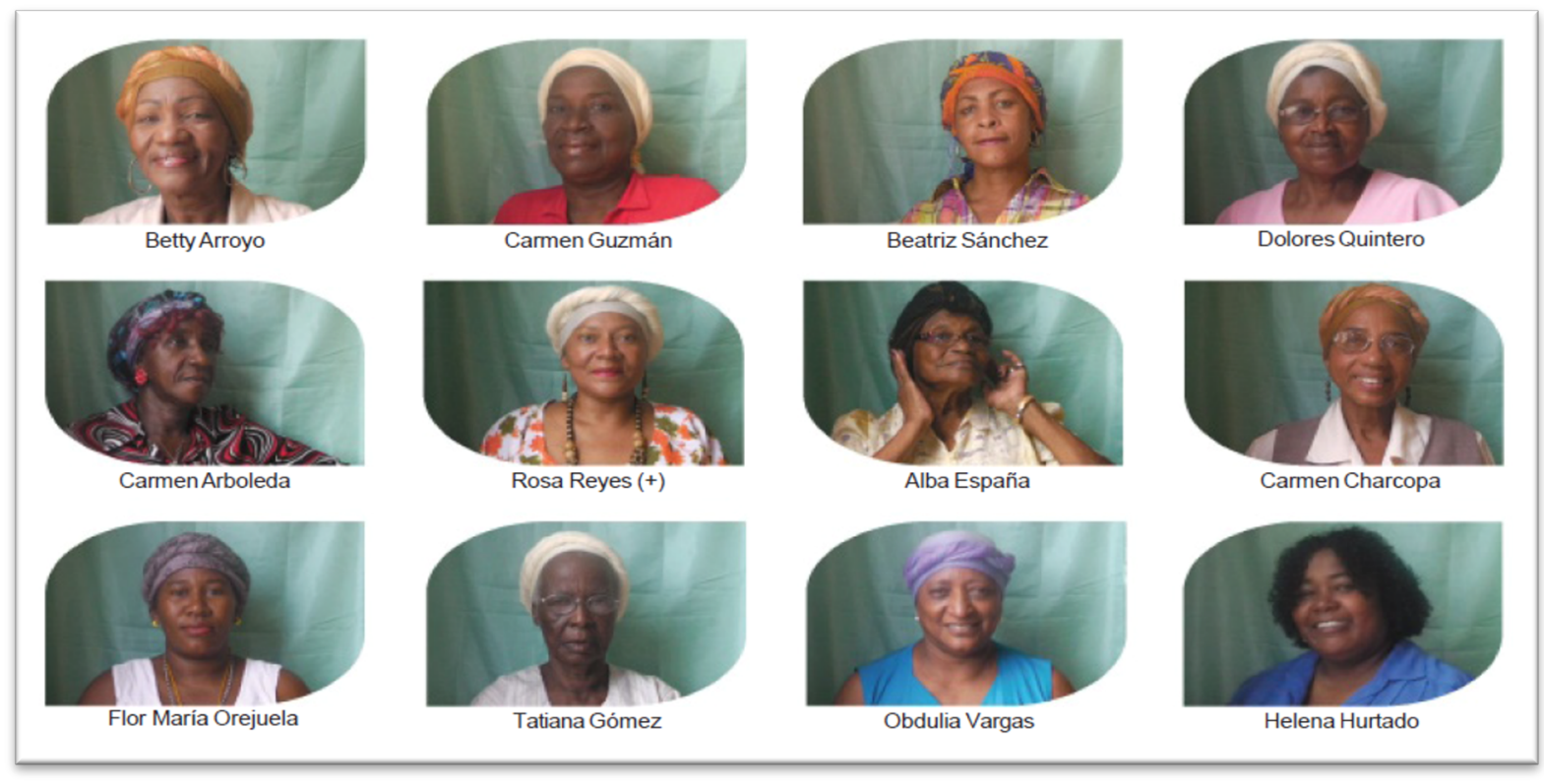

Fuente: https://www.bce.fin.ec (2017)

\section{Finanzas}

Las mujeres de la agrupación construyeron su propia caja de ahorros a partir de una mínima contribución semanal que fue fomentando en ellas el espíritu de ahorro.

"Desde que empezamos a organizarnos, construimos una caja de ahorros donde guardábamos 25 centavos a la semana, con lo que podíamos gestionar pequeños préstamos que servían para solucionar nuestros problemas domésticos cotidianos como por ejemplo comprar el cilindro de gas que para nosotras y nuestras familias constituía la diferencia entre comer o irnos a dormir con el estómago vacío" (Testimonio JR).

Después de 2 años de funcionamiento, la caja de ahorros tenía 83 socias y el ahorro general había crecido a 6 mil dólares. Recibiendo la ayuda en el 2010 de la Fundación Inter-Americana (FIA), con una consultoría técnica para crear una propuesta que les permitiría fortalecer sus liderazgos y su identidad afroecuatoriana. Más tarde, recibieron la donación de 24 mil dólares para su caja de ahorro, lo que las obligó a plantearse la necesidad de contar con un reglamento interno y la redistribución del ahorro general en 12 cajas de ahorro y crédito para que, cada una de las liderezas responsables, se encargara de realizar la administración y las gestiones de cobranza respectivas.

Cada caja de ahorro contaba con 32 socias, su propio reglamento que reflejaba las particularidades de su sector, siempre apegado al reglamento general; además de la administración de una lideresa con conocimientos sólidos en el manejo de los créditos y que además gestionaba actividades para atender los problemas cotidianos propios de las socias. Con esta estrategia se logra diversificar los liderazgos y asumir responsabilidades para que el éxito de las cajas de ahorro sea compartido, garantizando la transparencia en el manejo del dinero.

La gestión de la Caja de Ahorro y Crédito se realizaba de la siguiente manera:

- La Asamblea General recibía las solicitudes de créditos

- El Comité de Crédito evaluaba las solicitudes y recomendaba su aprobación. 
- Existía un Comité de Vigilancia que se reunía cada 3 meses para analizar los criterios utilizados para la aprobación de los créditos, de esta forma se garantizaba la transparencia y que los criterios fueran respetados; por ejemplo que no existiera favoritismo por motivo de parentezco.

\section{Emprendimiento}

En el año 2002, la Agrupación Mujeres Progresistas inaugura el nuevo espacio físico para el Centro Empresarial denominado "Mujeres Emprendedoras".

Los principales logros fueron:

- Mujeres dueñas de sus propios negocios

- Incidir sobre la independencia económica

- Liderazgo y bienestar en el hogar

- Reducción de la violencia intrafamiliar

- Impulsar la economía del sector con una variedad de emprendimientos

- Elevar la autoestima de la comunidad

- El Centro Empresarial cuenta con los siguientes servicios:

- Centro de capacitación: liderazgo y empresarial

- Centro de Computo Comunitario

- Punto de Apoyo Comunitario Jurídico

- Caja de Ahorro y Crédito para emprendimientos

Según manifiestan sus miembros, detrás de cada logro, existió el desafío constante por sostener el proceso de forma integral: social, comunitario, económico, con un enfoque de género y derechos humanos.

Figura 3

Centro Empresarial "Mujeres Emprendedoras"

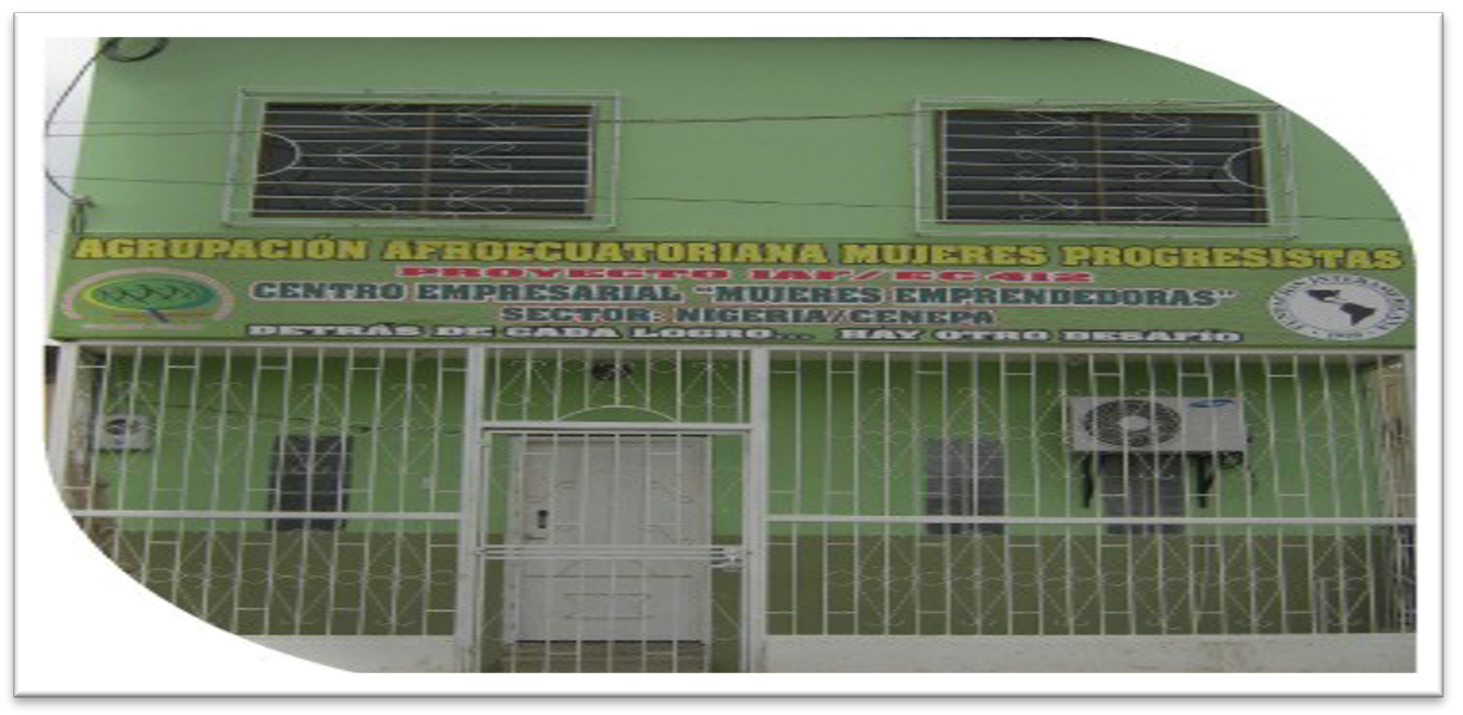

Fuente: https://www.bce.fin.ec (2017)

Para el año 2014, Mujeres Progresistas estaba posicionada como una organización de base comunitaria que había logrado fortalecer a 256 mujeres afrodescencientes para que administraran sus propios negocios en los sectores de Cenepa y Nigeria, zonas de extrema pobreza y hacinamiento en la Isla Trinitaria de la ciudad de Guayaquil. 
En alianza estratégica con la Universidad Politécnica del Litoral, levantaron un estudio de factibilidad para identificar los riesgos de competitividad de los emprendimientos y así evitar conflictos entre las compañeras. Para ello, realizaron un mapeo comunitario sobre la ubicación geográfica de cada negocio en todo el sector; con esta información se comenzó a otorgar créditos para nuevos negocios en lugares que permitieran descentralizar el mercado y así brindar la oportunidad de que todas las socias pudieran vender sus productos, recuperar su inversión, ganar su utilidad y pagar a tiempo el crédito.

Figura 4

Emprendimientos de las socias

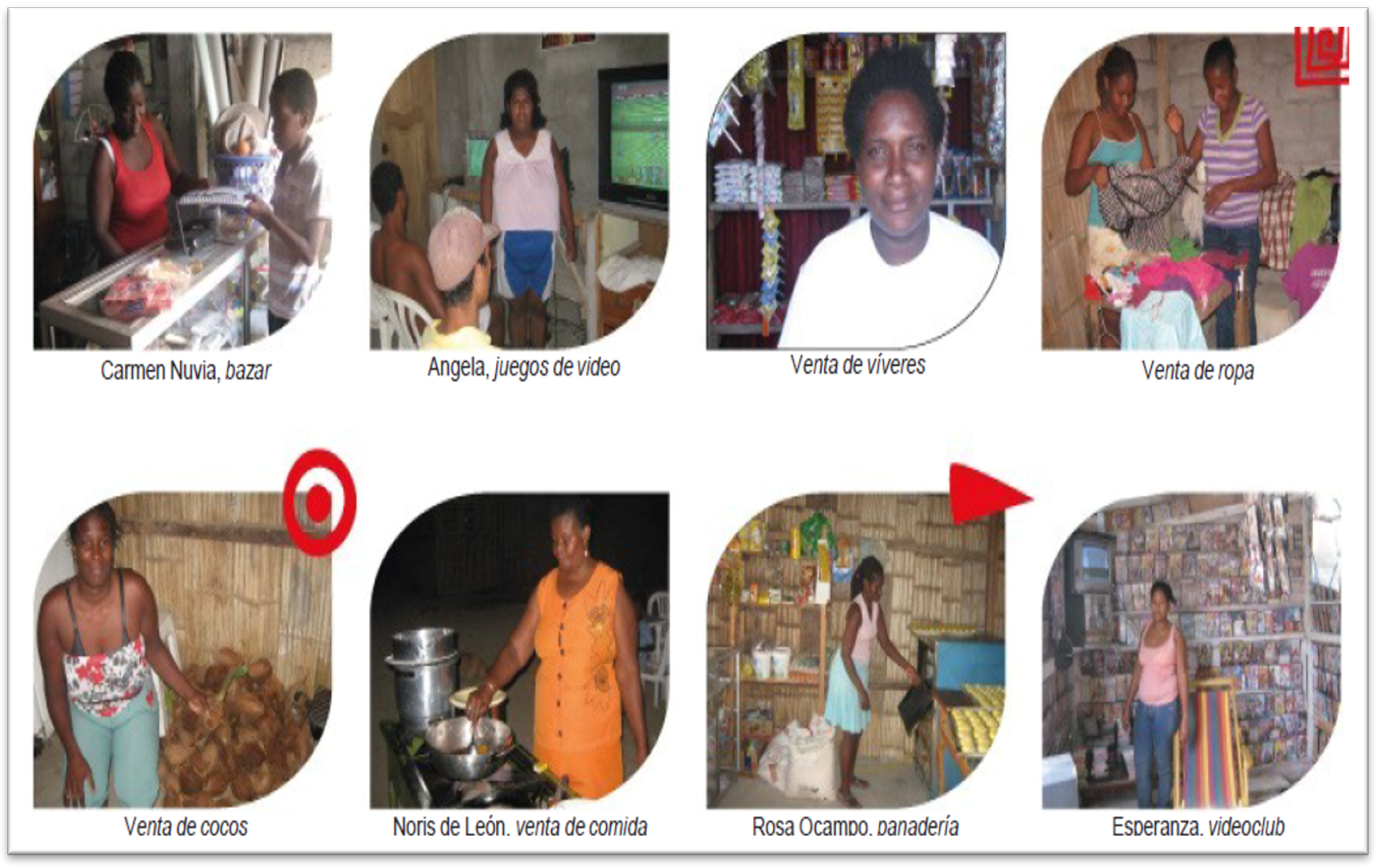

Fuente: https://www.bce.fin.ec (2017)

\section{Capacitación}

Las mujeres afroecuatorianas tienen limitado acceso a los espacios formales de educación y la mayoría no logra culminar los estudios básicos; valoramos nuestros saberes y conocimientos tradicionales pero, por razones de discriminación muchas no hemos podido ejercer este derecho.

En el marco del Proyecto "Educación Popular" del Ministerio de Educación, las socias pudieron tomar clases, con una profesora y un supervisor, delegados del proyecto, en un horario flexible que les permitiera ahorrar el dinero del transporte y disponer de tiempo para las labores domésticas y el cuidado de los hijos. Al finalizar, 27 mujeres terminaron la escuela y 16 se graduaron de bachiller y siguieron su educación secundaria por cuenta propia.

El centro de capacitación también ofertaba el programa para "Liderazgo y Manejo de Estudios de Mercado"; con la aprobación del ciclo, cada socia terminaba con su propio plan de inversión y únicamente de esta forma se accedía al crédito. 


\section{Tecnología}

El centro de cómputo comunitario empezó atendiendo un promedio de 42 personas diariamente. Con la implementación de este servicio se logró:

Capacitar a 103 mujeres en el uso de la tecnología con equipos de cómputo de última generación.

Facilitar herramientas para que las socias se vincularan con el mundo digital y pudieran ayudar a sus hijos con las tareas.

Brindar un servicio cercano y seguro para los hijos de las socias y en general para los niños, niñas, adolescentes y jóvenes del sector, quiénes ya no tenían que movilizarse para hacer sus investigaciones escolares.

Convertir el espacio en un referente importante para que la comunidad tenga acceso a la tecnología.

\section{Asesoría Legal}

En el año 2013 mediante un convenio tripartito entre el Alto Comisionado de las Naciones Unidas para los Refugiados (ACNUR), el Comité Permanente de los Derechos Humanos de Guayaquil y la Agrupación Afroecuatoriana "Mujeres Progresistas", se puso en marcha un punto de apoyo comunitario jurídico de Derechos Humanos que funcionaba en la sede de la organización. Este proyecto se ejecutó durante 2 años y permitió contar con profesionales que brindaban asesoría legal 3 veces a la semana, para atender casos de violencia intrafamiliar, violación de derechos humanos y discriminación.

Los logros alcanzados fueron:

- ACNUR fortaleció económicamente la caja de ahorro y crédito para potenciar los emprendimientos de las familias en calidad de refugiados.

- Tres familias refugiadas en situación de riesgo fueron enviadas a otros países a través del sistema de acogida.

- Se atendieron 184 familias en asesoría legal y se fortalecieron 23 emprendimientos de las mujeres refugiadas.

- Se visibilizó la violencia intrafamiliar debido a que las mujeres acudían a realizar las denuncias y se receptaron también demandas por pensiones alimenticias.

- Se implementó además un espacio para consejeria entre parejas y apoyo terapéutico.

\section{Asociatividad}

En 1996, se da cita el Comité Pro-mejoras del sector Nigeria y acuden 19 mujeres constituyéndose como una organización de hecho que buscaba incidir por servicios básicos como alcantarillado, agua potable y luz eléctrica para el sector.

En 1999, Mary Quiñonez, servidora pública del Ministerio de Bienestar Social e impulsa la obtención de la vida jurídica de la Agrupación Afroecuatoriana "Mujeres Progresistas", la cual es otorgada por registro público el 10 de mayo, siendo Daysi Vivero la primera presidenta cuyo periodo se extendió por 12 años.

En 2011, la Asamblea General solicita una reestructuración a los estatutos para incorporar, además del área operativa (Presidenta, Vicepresidenta, Tesorera, Secretaria y Vocales), el área administrativa que constaba de Coordinación de Proyectos y Contabilidad. En ambos casos las delegadas debían ser elegidas en Asamblea, quedando como responsables Sonnia España y Lorena Lozano, en cada uno de los cargos respectivamente.

En el año 2014, asume Cecibel Arboleda como Presidenta y se eliminan las figuras de socias fundadoras y socias inactivas respondiendo a la filosofía institucional que dictaba que todas las socias debían vincularse activamente 
a los procesos de la organización. En esta época también se incorpora un inventario de los bienes como patrimonio de la organización.

\section{Identidad étnica}

La Organización de las Naciones Unidas, a través de la Resolución No. 68/237, proclamó el Decenio Internacional de los Afrodescendientes, que inició el 1 de enero de 2015 y culminará el 31 de diciembre de 2024, con el tema "Afrodescendientes: reconocimiento, justicia y desarrollo".

Desde el año 2015, Mujeres Progresistas mantiene un convenio con Fundación Esquel en el marco del Programa de Fortalecimiento de Organizaciones de la Sociedad Civil, el cual consiste en capacitación técnica a través de la plataforma virtual Esquel Clic, consultorías de apoyo para el desarrollo de herramientas de gestión organizacional y la ejecución de un proyecto de incidencia política local.

Este programa permitió realizar una reingeniería interna de la estructura y procedimientos de la organización, pudiendo contar con:

- Diagnóstico situacional de la organización

- Plan de desarrollo organizacional

- Plan de sostenibilidad financiera

- Planificación estratégica y programática

- Plan comunicacional

- Asesoría Jurídica organizacional

- Talleres de formación y vocería a las socias

"Mujeres Progresistas" en convenio con Fundación Esquel, inició en marzo de 2016, la ejecución del proyecto "Decenio del pueblo afrodescendiente en el Ecuador" con el objetivo de elaborar un plan de acción que fortalezca las herramientas técnicas y formativas de 25 organizaciones afroecuatorianas y su incidencia frente a los organismos estatales (Consejo de Participación Ciudadana, Ministerio de Gestión Política y Secretaría Jurídica de la Presidencia) y exigir la implementación de políticas públicas que hagan posible que el Convenio que el país firmó con Naciones Unidas por el Decenio Internacional de los Afrodescendientes se haga efectivo.

\section{Hostería Comunitaria “África Mía”}

Empresa turística dedicada $100 \%$ a trabajar dentro de la Isla Trinitaria, a fin de mejorar la calidad de vida y promover la participación activa de las mujeres de la zona. Presta servicios de alojamiento, alimentación y organización de eventos.

Su modelo de gestión permite:

Atraer emprendedores que posean habilidades en Comunicación, Liderazgo y Actitud Positiva.

Iniciar proyectos con ellos y ellas para ofrecer alternativas de mejoramiento en su calidad de vida.

Identificar las ideas y oportunidades de negocios por medio de la creación de empresas, proyectos de emprendimientos y generación de empleos.

Analizar factores exógenos como los de índole económica, social, ambiental, política y factores endógenos como los recursos humanos, físicos y financieros. De esta forma se genera la Red Comunitaria de Emprendedores y un modelo de desarrollo sostenible para el emprendimiento. 
Figura 5

Hostería Comunitaria “Africa Mía”

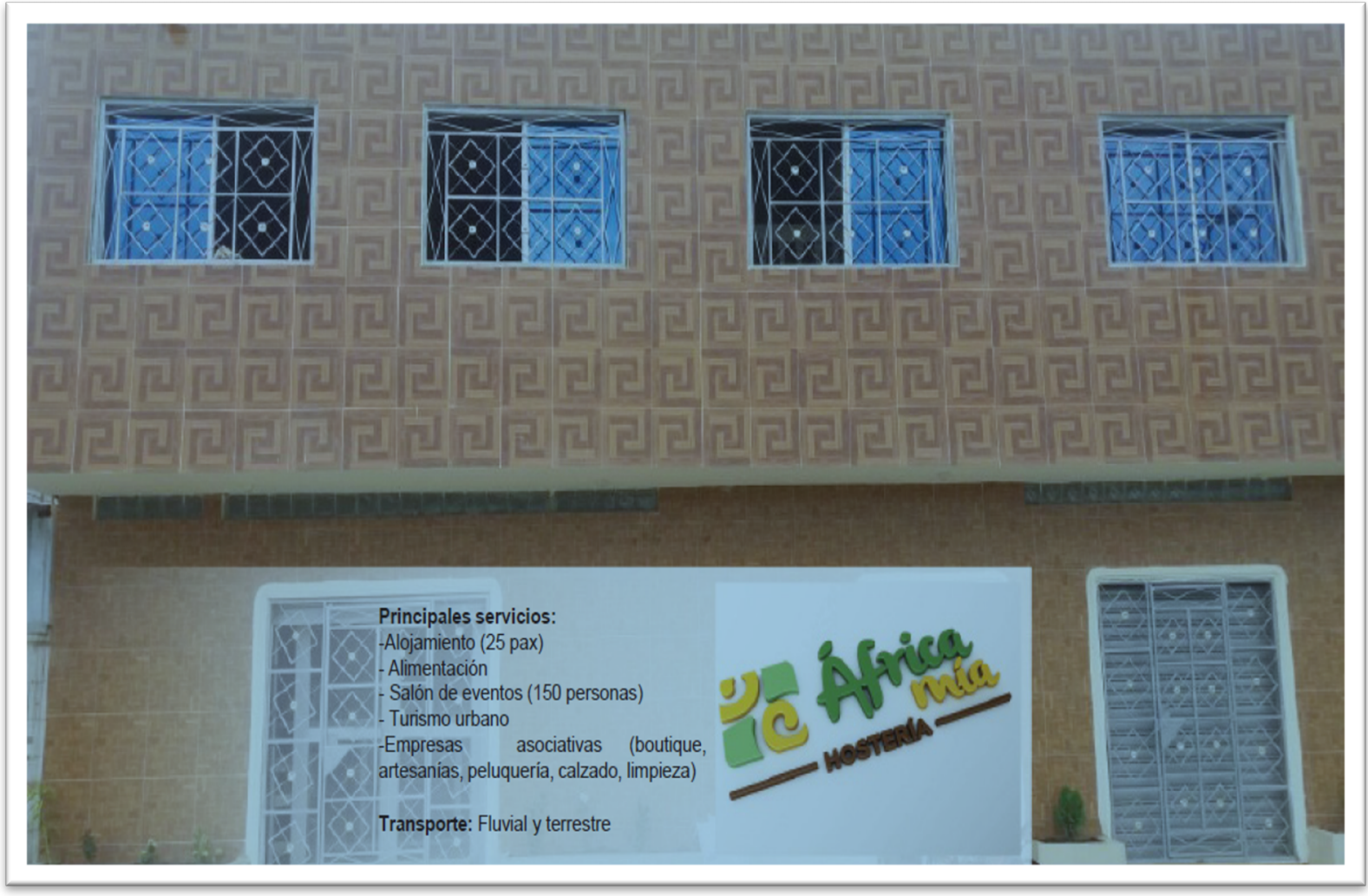

Fuente: https://www.bce.fin.ec (2017)

\section{Conclusiones}

A través del desarrollo de la investigación se encontró que existe una relación directa entre las microfinanzas y el desarrollo de las mujeres afro a toda escala. El impacto de éstas sobre las mujeres y más aún sobre la organización, ha sido significativamente positivo y les ha permitido generar excedentes para ser utilizados en la reinversión de sus emprendimientos y en la satisfacción de las necesidades básicas propias y de sus familias. Siendo lo más destacable la formación, la organización asociativa, la autonomía económica a traves del emprendimiento, la defensa de sus derechos y el orgullo por su etnia, puntales de su empoderamiento y de convertir una meta individual en un sueño colectivo.

"Cuando las mujeres manejamos nuestra propia economía somos capaces de tomar acciones para liberarnos de la violencia y reconocernos ser sujetas transformadoras de la realidad de nuestra comunidad" (Testimonio OP)

\section{Agradecimientos}

El presente artículo forma parte del Proyecto de Investigación "El costo de la feminidad: Discriminación de precios en el consumo de productos de cuidado personal. Una evidencia para la ciudad de Guayaquil" del Fondo Competitivo de Investigación, convocatoria FCl-2019, de la Dirección de Investigación, Gestión del Conocimiento y Posgrado de la Universidad de Guayaquil. 


\section{Referencias bibliográficas}

Agrupación Afroecuatoriana Mujeres Progresistas. (2017). África mía. Un ejercicio de emprendimiento social. Experiencia de desarrollo de base de las mujeres organizadas de la Isla Trinitaria, Guayaquil - Ecuador. 2003 - 2017. Obtenido de https://www.bce.fin.ec/images/BANCO_C_ECUADOR/PDF/03BrochureAAMPsonniaEspana.pdf

Araque, W., \& Vaca, J. (2011). Ecuador: propuestas para microfinanzas competitivas con vocación solidaria. En B. Balkenhol, \& A. L. Valazza, Microfinanzas y políticas públicas: objetivos de eficiencia para un sector responsable. Madrid: Editorial Plaza y Valdés.

Comisión Económica para América Latina y el Caribe (CEPAL). (Febrero de 2020). Mujeres afrodescendientes en América Latina y el Caribe. Deudas de Igualdad. Obtenido de https://repositorio.cepal.org/bitstream/handle/11362/43746/4/S1800190_es.pdf

Corporación Andina de Fomento. (Febrero de 2018). Inclusión Financiera de las Mujeres en América Latina. Situación actual y recomendaciones de política. Caracas: Corporación Andina de Fomento. Obtenido de https://www.perfil.com/noticias/50y50/las-mujeres-tienen-menos-acceso-al-credito-y-compran-menosdolares.phtml

Diario EL TELÉGRAFO. (9 de Febrero de 2012). Obtenido de https://www.eltelegrafo.com.ec/noticias/judicial/12/una-red-de-chulqueros-es-capaz-de-manejar-masde-15-millones

Diario EL TELÉGRAFO. (18 de Septiembre de 2012). Los afroguayaquileños. Obtenido de https://www.eltelegrafo.com.ec/noticias/guayaquil/10/los-afroguayaquilenos

Diario EL TELÉGRAFO. (Enero de 2020). Mujeres afro piden mayor reconocimiento. Obtenido de https://www.eltelegrafo.com.ec/noticias/sociedad/6/mujeres-afro-pedido-mayor-reconocimiento

Empresa Pública Municipal de Turismo, Promoción Cívica y Relaciones Internacionales de Guayaquil, EP. (Enero de 2020). Iglesia Cristo del Consuelo. Obtenido de https://www.guayaquilesmidestino.com/es/iglesias/delsur-de-la-ciudad/cristo-del-consuelo

Hernández-Sampieri, R., \& Mendoza Torres, C. P. (2018). Metodología de la investigación. Las rutas cuantitativa, cualitativa y mixta. Ciudad de México: Mc Graw Hill Education.

Hogar de Cristo Ecuador. (2012). Monte Sinaí "La herencia de los vulnerados". Guayaquil.

Instituto Nacional de Estadísticas y Censos. (2010). Censo Nacional de Población y Vivienda.

Portal FINDEV. (Febrero de 2020). https://www.findevgateway.org/es/pa\%C3\%ADs/ecuador.

Radio PERFIL. (Febrero de 2020). Las mujeres tienen menos acceso al crédito y compran menos dólares. Obtenido de https://www.perfil.com/noticias/50y50/las-mujeres-tienen-menos-acceso-al-credito-ycompran-menos-dolares.phtml

Sánchez Gordillo, O. (Febrero de 2020). El microcrédito para emprendimientos productivos a las mujeres que habitan en la Cooperativa Monte Sinaí de la ciudad de Guayaquil. Obtenido de http://repositorio.ug.edu.ec/bitstream/redug/5255/1/S\%C3\%A1nchez\%20Gordillo\%2C\%200linda\%20Celi a.pdf 
Superintendencia de Economia Popular y Solidaria. (Febrero de 2020). Apunte IV. Relatos de organizaciones solidarias femeninas. Obtenido de www.seps.gob.ec

Vera Santos, R. (Febrero de 2020). Mujeres afroecuatorianas en Quito: identidades, resistencia y acción política. Obtenido de https://revistas.flacsoandes.edu.ec/mundosplurales/article/view/2317

Yunus, M. (2006). El Banquero de los pobres. Los microcréditos y la batalla contra la pobreza en el mundo. En M. Yunus, El Banquero de los pobres. Los microcréditos y la batalla contra la pobreza en el mundo. (pág. 73-74-259). Barcelona, España: Paidós Ibérica, S.A.

Esta obra está bajo una Licencia Creative Commons

Attribución-NoCommercial 4.0 International

(cc) BY-NC 